\title{
Improvement in the Biological Properties of Titanium Surfaces with Low-Temperature Plasma
}

\author{
Yu-Hwa Pan ${ }^{1,2,3,4, \dagger}$, Wan-Ling Yao ${ }^{1, \dagger}{ }^{+}$Jerry Chin Yi Lin ${ }^{1}$, Eisner Salamanca ${ }^{1}$, Pei-Yo Tsai ${ }^{1}$, \\ Sy-Jye Leu ${ }^{5}$, Kai-Chiang Yang ${ }^{6}{ }^{(0)}$, Haw-Ming Huang ${ }^{1}$, Nai Chia Teng ${ }^{1}$ and Wei-Jen Chang ${ }^{1,7, *}$ \\ 1 School of Dentistry, College of Oral Medicine, Taipei Medical University, Taipei 110, Taiwan \\ 2 Department of General Dentistry, Chang Gung Memorial Hospital, Taipei 106, Taiwan \\ 3 Graduate Institute of Dental \& Craniofacial Science, Chang Gung University, Taoyuan 333, Taiwan \\ 4 School of Dentistry, College of Medicine, China Medical University, Taichung 404, Taiwan \\ 5 Department of Microbiology and Immunology, School of Medicine, College of Medicine, \\ Taipei Medical University, Taipei 110, Taiwan \\ 6 School of Dental Technology, College of Oral Medicine, Taipei Medical University, Taipei 110, Taiwan \\ 7 Dental Department, Taipei Medical University, Shuang-Ho hospital, Taipei 235, Taiwan \\ * Correspondence: cweijen1@tmu.edu.tw; Tel.: +886-2-27361661 (ext. 5148) \\ + Authors' work were equal contributed.
}

Received: 19 July 2019; Accepted: 27 August 2019; Published: 28 August 2019

check for updates

\begin{abstract}
Peri-implantitis has become a common complication, accompanied by soft tissue inflammation. Porphyromonas gingivalis infection is the major cause of inflammation and progressive bone loss in the jaws. The surface property of titanium implants is a key factor in the alteration of osseointegration and P. gingivalis adhesion. However, the interplay between $P$. gingivalis and the surface properties of implants, subjected to different treatments, is not well described. Therefore, we focused on the surface properties of titanium implants; titanium disks that were autoclaved alone were used as controls. Those that were autoclaved and then subjected to low-temperature plasma (LTP) at $85 \mathrm{~W}$ and $13.56 \mathrm{MHz}$ and with $100 \mathrm{mTorr}$ of argon gas at room temperature for 15 min formed the experimental group. LTP-treated disks had smoother surfaces than the control group disks. The physical properties, such as scanning electron microscope (SEM), energy dispersive X-ray spectrometer (EDX), and X-ray photoelectron spectroscopy (XPS), demonstrated the surface composition was changed after LTP treatment. Further, osteoblastic cell proliferation enhancement was observed in the LTP-treated titanium surfaces. The results also revealed relatively less P. gingivalis adhesion to the LTP-treated disks than on the control disks on spectrophotometry and SEM. These findings clarified that $P$. gingivalis adhesion is reduced in implants subjected to LTP treatment. Thus, LTP treatment of peri-implantitis with the settings used in the present study is an option that needs further investigation.
\end{abstract}

Keywords: low-temperature plasma; surface modification; osseointegration; P. gingivalis; titanium

\section{Introduction}

The development of dental implants is a milestone in clinical dental therapy [1-4]. Titanium (Ti) has been considered a material suitable for dental implant fixtures and abutments for oral rehabilitation [5,6]; however, many biological and physical complications can occur after dental implantation [7-9]. One of the major reasons for these complications is microbial infection that can damage oral tissues [10-14]. Peri-implantitis, one of the most common conditions triggered by pathogenic infections, is an inflammatory disease that manifests as a site-specific lesion in the soft tissue with bone loss around an osseointegrated implant [15-19]. It is induced by microbial proliferation on 
biofilms attached to the implant surfaces [20]. Previous studies have demonstrated that microorganisms causing peri-implantitis include spirochetes and gram-negative anaerobes, particularly Porphyromonas gingivalis $[10,21,22]$. P. gingivalis has been identified as a periodontal pathogen that is not only commonly present in most patients with severe diseases, such as periodontitis, but also is capable of governing host cells to produce virulence factors [23]. The overall increase in the prevalence of peri-implantitis suggests that anaerobic plaque bacteria play a role in its progression [24,25]. Peri-implantitis causes bone loss around the implant that eventually leads to implant loss. Thus, treatment involves the regeneration of the soft and hard tissues for the restoration of implant support along with the prevention of bacterial infections. Microbial infection plays a major role in dental implant failure; therefore, effective prevention of and reduction in bacterial accumulation on the implant surfaces are the main priorities in dental therapy.

In order to investigate the appropriate method for reducing the incidence of peri-implantitis, investigators have focused on different aspects of decreasing pathogen accumulation during plaque and calculus formation [16-18]. Moreover, to improve conditions at the bone-implant interface, several studies on surface treatment have demonstrated effective and efficient removal of plaque and calculus with metal curettes and conventional ultrasonic scalers [26-32]. However, although the use of nonmetallic instruments and air abrasives causes less damage to the implant surface, it does not completely eliminate plaque and calculus $[29,33]$.

Previous studies have shown that low-temperature plasma (LTP) treatment is frequently used for cleaning, preparing, and modifying biomaterial and implant surfaces in the field of dentistry [34]. The advantages of LTP treatment include reduced contact angle, spread of osteoblastic cells, and no residues on the implant surface; however, physicochemical changes, including changes in the content of hydrocarbon and functional hydroxyl groups as well as surface free energy levels have been observed in implants. According to some reports on the effect of LTP treatment on Ti surfaces, LTP treatment improves cell adhesion by changing the surface roughness, wettability, and functional protein configuration of implants as well as by the creation of biofunctional groups [35-37]. Moreover, the combination of LTP treatment with fibronectin grafting has increased the surface hydrophilicity and surface roughness of Ti disks, thereby further enhancing cell adhesion as well as enhancing cell migration, proliferation, and differentiation [38-40]. Owing to these kinds of interactions between dental implant surfaces after LTP treatment and cells, particularly odontoblasts, LTP is a promising treatment for stimulating re-osseointegration of dental implants after peri-implantitis. As some in vitro studies have concluded, argon plasma technology could be used efficiently to sterilize a peri-implantitis-contaminated implant surface [41] and to promote osteoblast attachment and spreading [42]. In canine and rabbit in vivo studies, LTP has been used only for implant insertion where it has demonstrated enhanced osseointegration and, hence, higher bone formation [43-45].

However, the effects of various physical treatments of surface implants against $P$. gingivalis have not been intensively described. In this study, the effects of LTP treatments on Ti surfaces were evaluated. The surface properties and P. gingivalis adhesion, as well as colony formation on Ti surfaces with LTP treatment, were investigated.

\section{Materials and Methods}

\subsection{Titanium Disk Preparation}

Grade II Ti disks (BioTech One, Inc., Taipei, Taiwan), $10 \mathrm{~mm}$ in diameter and $1 \mathrm{~mm}$ thick, were ultrasonically cleaned in a detergent solution for $15 \mathrm{~min}$ and in pure distilled water for another $15 \mathrm{~min}$. The same procedure was then performed with acetone for $15 \mathrm{~min}$ and then twice in pure distilled water. Lastly, the well-cleaned titanium disks were autoclaved at $121{ }^{\circ} \mathrm{C}$ for $20 \mathrm{~min}$ and dried. The disks ( $n=6$ for each test) were divided into the following two groups: the control (Ctrl-Ti) group consisted of disks subjected only to high pressure and high temperature (autoclaving), and the LTP-treated (LTP-Ti) group consisted of disks subjected to LTP treatment after autoclaving. 


\subsection{Low-Temperature Plasma Treatment}

In the LTP-treated group, disk surfaces were cleaned with LTP (PJ Plasma Surface Treatment System; AST Products Inc., North Bellericca, MA, USA) at $85 \mathrm{~W}$ and $13.56 \mathrm{MHz}$ and with $100 \mathrm{mTorr}$ of argon gas at room temperature for $15 \mathrm{~min}$ [39].

\subsection{Scanning Electron Microscopic Analysis of Surfaces}

Each disk surface was coated with gold nanoparticles and observed under a 20-kV scanning electron microscope (SEM, SU-3500; Hitachi High-Technologies, Kyoto, Japan). Images were taken from at least five random, nonoverlapping specimen areas at $1000 \times$ magnification.

\subsection{Energy Dispersive Spectrometry}

Elemental composition analyses of the samples were performed with field emission scanning using the same SEM apparatus coupled with an energy dispersive X-ray spectrometer (EDS, SU-3500; Hitachi High-Technologies, Kyoto, Japan).

\subsection{X-Ray Photoelectron Spectroscopy}

X-ray photoelectron spectroscopy (XPS; ESCA system; VG Scientific, West Sussex, UK) with a 1486.6-eV monochromatic X-ray source was used in the elemental and chemical analyses of the treated surfaces. This technique is widely used to understand the details of both surface element distribution and chemical bonding and has been identified as a surface-sensitive quantitative spectroscopic method of measuring the elemental composition in the range of parts per thousand, chemical state, empirical formula, and electronic state of elements that exist within a material [46]. Spectra were collected at an electron take-off $90^{\circ}$ angle to the disk surfaces.

\subsection{Examination of Surface Wettability}

In order to assess surface wettability, the contact angle of the substrate to the given liquid (water droplet) was measured. The contact angle is the angle between the line that represents the apparent solid surface and the tangent to the liquid-vapor interface. A linear goniometer (Digidrop Goniometer; GBX, Romans, France), comprising a base platform, a 35-mm camera, a sample holder, and an external lighting system to illuminate the disk, was used to measure this angle. A 4- $\mu$ L water droplet (Milli-Q; Millipore Sigma, Bedford, MA, USA), filtered at $20^{\circ} \mathrm{C}$, was applied to the test surface. Each developed slide was projected on a standardized tracing table, after which the image was tracked, and the contact angle was measured. Advancing contact angles for each water droplet were calculated and measured.

\subsection{Examination of Surface Roughness}

Average surface roughness $(\mathrm{Ra})$ of the Ti disks was measured using a profilometer (TR200, An-Bomb Instrument Co., Ltd., Tinan, Taiwan). The average surface roughness value was described in micrometers $(\mu \mathrm{m})$. The program was set as per the manufacturer's protocol.

\subsection{Cell Viability}

The cells were cultured over periods of 24,48 , and $72 \mathrm{~h}$ at $5 \% \mathrm{CO}_{2}, 37^{\circ} \mathrm{C}$, and $100 \%$ humidity. The 0-h starting point was defined as the time when the MG-63 cells on the differently treated Ti surfaces were cultured in the prepared Dulbecco's modified Eagle's medium (HyClone, Logan, UT, USA) and harvested. The spectrophotometric methyl tetrazolium assay was performed with the Cell Proliferation Kit I MTT (Cat. No. 11465007 001; Roche, Mannheim, Germany), following a protocol that was previously described in our laboratory [47]. 


\subsection{Porphyromonas gingivalis Culture}

ATCC $^{\circledR} 33277$ bacteria strain (Microbiologics Ltd., St. Cloud, MN, USA) was anaerobically cultured on tryptic soy agar (ATCC Medium: 260 Trypticase soy agar, Manassas, VA, USA) at 37 ${ }^{\circ} \mathrm{C}$ for $72 \mathrm{~h}$. Subsequently, trypticase, soy broth was used to dilute the bacterial concentration, and $10^{6} \mathrm{CFU} / \mathrm{mL}$ of broth was used for each experiment.

\subsection{Quantification of Substrate and Products}

The adhesion of Porphyromonas gingivalis was quantitatively measured by optical density. After incubation, bacterial adhesion on the discs was quantified via spectrophotometric evaluation every $24 \mathrm{~h}$ for $5 \mathrm{~d}$. For OD measurements, $1 \mathrm{~mL}$ of new growth medium was added onto each disk surface and vortexed. The OD of the adherent bacteria biomass of each well was measured at $660 \mathrm{~nm}$ and $570 \mathrm{~nm}$ using a spectrophotometer reader (GENESYS ${ }^{\mathrm{TM}} 10$ Series Spectrophotometer, Thermo Fisher Scientific, Waltham, MA, USA) [48]. Optical density measurement is commonly used to establish correlations among biomass concentration, bacterial growth, and bacteria cell population in any culture [49]. It is defined as the absorbance per unit length, and the bacterial concentration is often related to the turbidity of a liquid culture determined by measuring the absorbance [50].

\subsection{Bacteria Counting Analysis}

Subsequent to the treatment of titanium disk with only autoclaving (Ctrl-Ti group) and treatment with low-temperature plasma after autoclaving (LTP-Ti group), they were exposed to P. gingivalis $\left(10^{6} \mathrm{CFU} / \mathrm{mL}\right)$ via incubation. The LTP-Ti group disks were harvested every $24 \mathrm{~h}$ during the $5 \mathrm{~d}$. Thereafter, each disk was coated with gold nanoparticles and observed under a 20-kV SEM (SU-3500) following the scanning electron microscopic analysis of the surfaces protocol, as described previously.

\subsection{Statistical Analyses}

All the experimental values are presented as means \pm standard errors for at least 3 independent recordings. Data were analyzed with the SPSS software (Ver. 18, IBM Corp., Armonk, NY, USA) and EXCEL.

\section{Results}

\subsection{Surfaces Electron Microscopic Analysis}

Low-temperature plasma-treated titanium had a smoother surface. The SEM examination revealed irregular surfaces on the Ctrl-Ti disks (Figure 1A) and smoother surfaces on the argon LTP-Ti disks (Figure 1B).

A) Ctrl-Ti

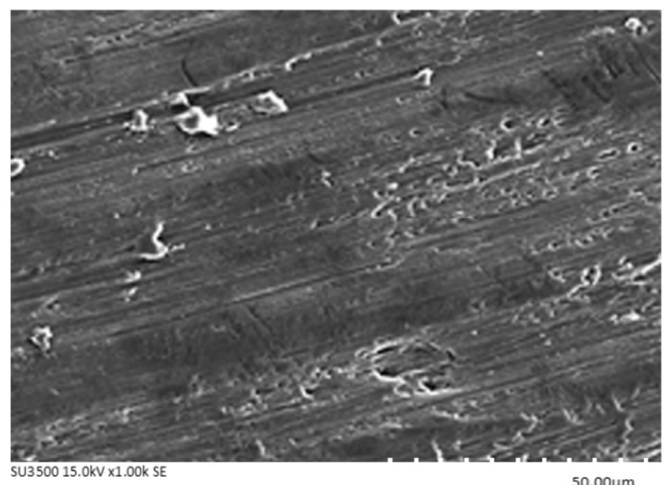

B) LTP-Ti

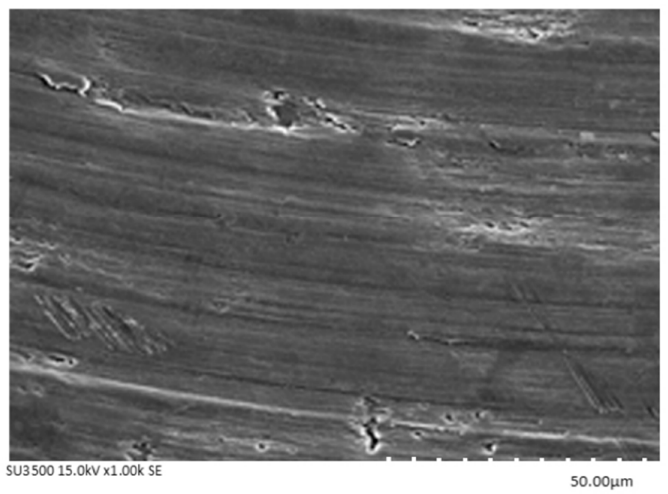

Figure 1. Implant surface images obtained with scanning electron microscopy (SEM). (A) Surface of the titanium disk treated with only autoclaving (Ctrl-Ti group). (B) Surface of the titanium disk treated with low-temperature plasma (LTP) after autoclaving (LTP-Ti group). 


\subsection{Energy Dispersive Spectrometry}

Atomic configuration showed no differences between the two groups of titanium disks treated with energy dispersive spectrometry analysis. The EDS analyses showed the numbers of elements in both the groups of Ti disks. Neither group showed any remarkable difference in the elements (Table 1). In the component configuration, only the carbon weight percentages were significantly different between the two groups.

Table 1. Energy dispersive spectrometer values.

\begin{tabular}{cccc}
\hline \multirow{2}{*}{ Treatment } & \multicolumn{3}{c}{ Component } \\
& Ti & O & C \\
\hline Crtl-Ti & 93.62 & 4.70 & 2.83 \\
LTP-Ti & 92.80 & 5.70 & 1.9 \\
$p$-value & 0.302 & 0.131 & $* 0.038$ \\
\hline
\end{tabular}

The main elements on the titanium (Ti) disks that were only treated by autoclave (Ctrl-Ti condition) and those treated with low-temperature plasma (LTP) after autoclaving (LTP-Ti condition). Each value represents the percentage by weight. ${ }^{*} p<0.05$.

\subsection{X-ray Photoelectron Spectroscopy}

The surfaces of the treated titanium disks showed similar elements with the XPS examination. The XPS examination was performed to analyze the changes in the elements in each disk (Figure 2). The two groups of the Ti disks showed no significant differences after the treatments, indicating that the elemental composition in both the groups was sustained with high similarity.
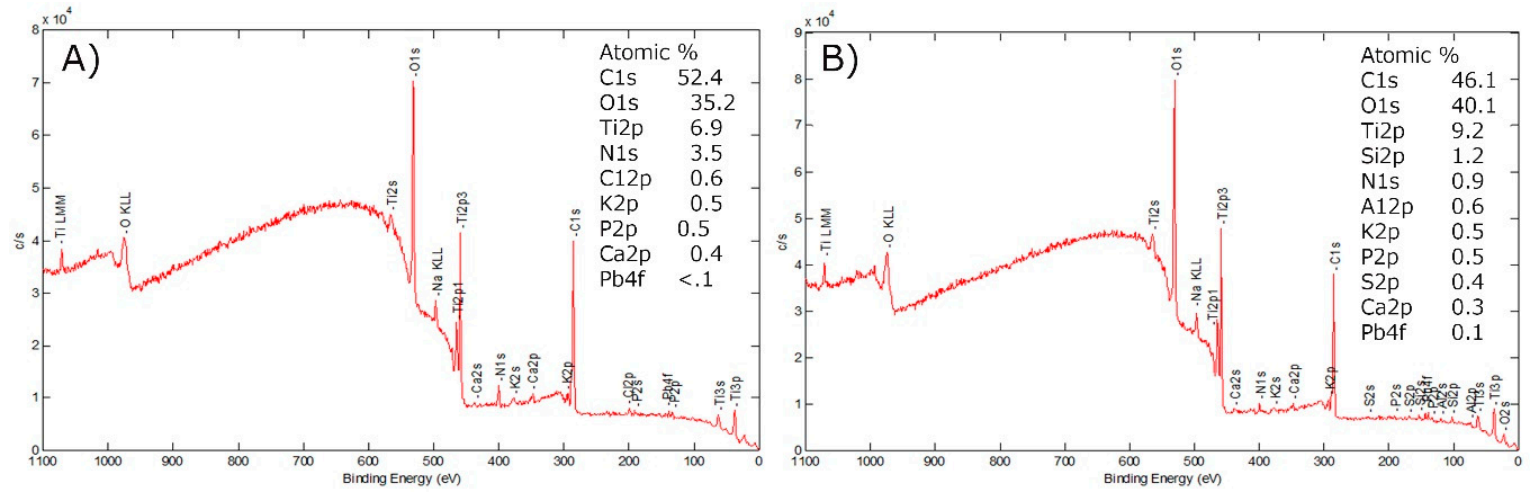

Figure 2. X-ray photoelectron spectroscopy (XPS) analysis of the treated titanium disks. The XPS survey spectrum shows the atomic ratio of each treated disk. (A) Control disks (Ctrl-Ti condition), subjected only to autoclaving. (B) Disks treated with low-temperature plasma (LTP; LTP-Ti condition) after autoclaving.

\subsection{Examination of Surface Wettability}

Low-temperature plasma-treated titanium disks have better surface wettability. In order to address the surface hydrophilicity of the two groups of disks, surface wettability was analyzed with contact angle measurements (Figure 3). Lower contact angles indicated that the disk surface was hydrophilic, and the water droplet appeared flatter [39]. The contact angles in the LTP-Ti disks were lower than those in Ctrl-Ti disks (autoclaved only), indicating that the LTP-treated surface had superior hydrophilicity and significantly high surface wettability. 


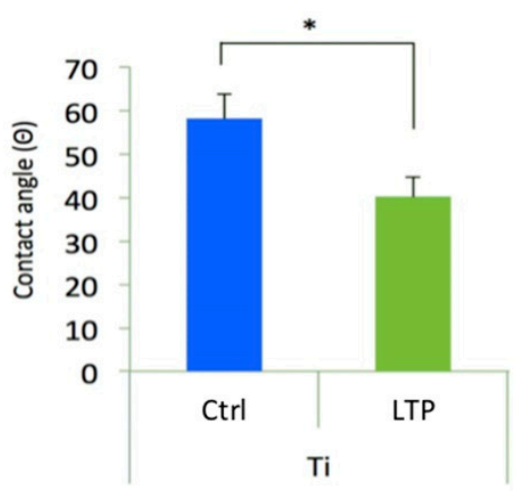

Figure 3. Measurement of the contact angle on each treated surface. Contact angle $(\theta)$ was considered the index of surface wettability, indicated by the angle formed by a water droplet on the disk surface. Quantitative analysis indicated that the surface wettability of low-temperature plasma (LTP)-treated (LTP-Ti) disks was improved in comparison with the control (Ctrl-Ti) disks (autoclaved only). ${ }^{*} p<0.05$.

\subsection{Surface Roughness Examination}

Low-temperature plasma-treated titanium disks have smoother surfaces. Figure 4 depicts the surface roughness measurements obtained from each disk. The average surface roughness of both the groups of disks after the treatments was quantified. The values obtained from disks in the Ctrl-Ti and LTP-Ti groups were $0.167 \pm 0.004 \mu \mathrm{m}$ and $0.092 \pm 0.007 \mu \mathrm{m}$, respectively (Figure 4). These findings indicate that LTP-Ti disks were significantly smoother than the Ctrl-Ti disks $(p<0.05)$.

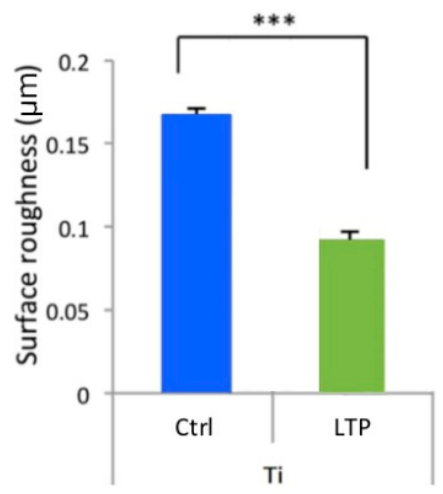

Figure 4. The effect of various treatments on the surface roughness of titanium disks. Roughness was lower in the disks treated with low-temperature plasma (LTP; LTP-Ti condition), indicating that they had smoother surfaces than the control (Ctrl-Ti) disks. ${ }^{*} p<0.05,{ }^{* *} p<0.01,{ }^{* * *} p<0.001$.

\subsection{Cell Viability}

Low-temperature plasma-treated titanium disks have better cell viability. According to previous results, Ti surfaces treated with LTP were flat and had high wettability; this might provide an environment conducive to cell culture. MG-63, a human cell line derived from osteosarcoma, was used to examine cell growth on the Ti disks in this study (Figure 5). In order to measure cell viability, cells were harvested after 24, 48, and $72 \mathrm{~h}$ for the MTT assay. The results showed that the LTP-Ti disks expressed significantly more cell growth than the Ctrl-Ti disks. This observation indicated higher cell viability after LTP treatment; therefore, the decrease in surface roughness enabled initial cell adhesion. Thus, LTP treatment produced an environment for cell attachment and enhanced cell growth. 

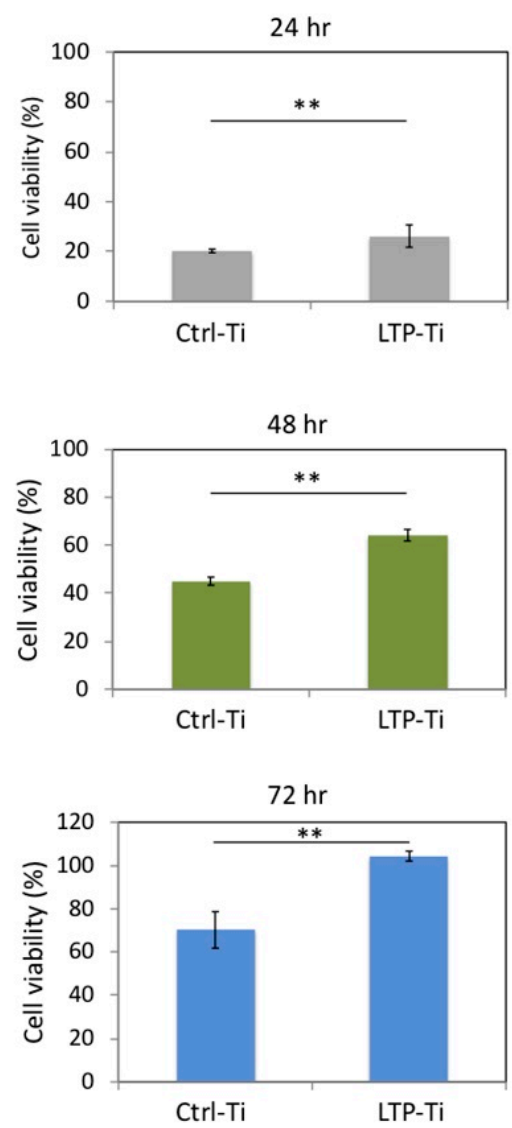

Figure 5. Viability of the MG-63 cells on treated titanium disks according to the MTT assay.

Cells were harvested after 24,48 , and $72 \mathrm{~h}$ of culture for the MTT assay and for measuring the absorbance at $570 \mathrm{~nm}$. Ctrl-Ti, control condition (autoclaving only). LTP-Ti, autoclaving followed by low-temperature plasma (LTP) treatment. ${ }^{* *} p<0.01$.

\subsection{Porphyromonas Gingivalis Adhesion and Growth}

Low-temperature plasma-treated titanium disks reduce the adhesion of $P$. gingivalis. In order to examine the $P$. gingivalis behavior on each Ti disk, the two groups of Ti disks were exposed to P. gingivalis at $10^{6} \mathrm{CFU} / \mathrm{mL}$ and collected at the indicated time points (Figure 6). At each time point, the attachment of $P$. gingivalis to the treated Ti disks was quantified. During $5 \mathrm{~d}$ after exposure, the LTP-treated disks had relatively low $P$. gingivalis adhesion.

Porphyromonas gingivalis colonies grow less on low-temperature plasma-treated titanium disks. Bacterial growth after their adhesion to the disks was examined. Each specimen was collected at the indicated time after treatment and subjected to SEM analysis (Figure 7). LTP-Ti disks demonstrated less bacterial colony formation than Ctrl-Ti disks, consistent with the findings depicted in Figure 6.

During the $5 \mathrm{~d}$ of observation, the quantified data demonstrated a remarkable increase in the accumulation of $P$. gingivalis in all the disks $3 \mathrm{~d}$ after exposure (Table 2), implying that the initial exposure to the bacteria resulted in its attachment to the disks. The complete data suggest that surface roughness plays a critical role in the initial adhesion of $P$. gingivalis, leading to infection. 


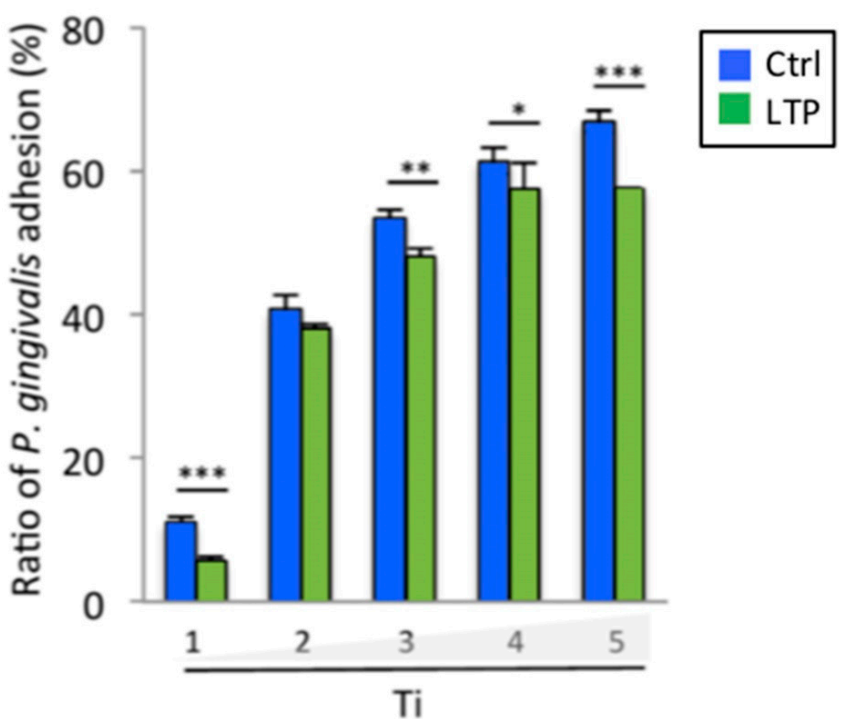

Figure 6. Adhesion of Porphyromonas gingivalis to the surfaces of the titanium disks after treatment. After treatment, each disk was exposed to $P$. gingivalis $\left(10^{6} \mathrm{CFU} / \mathrm{mL}\right)$, cultured for up to $5 \mathrm{~d}$, and harvested at the indicated time points. At $1 \mathrm{~d}$ and other time points after exposure, the disks treated with low-temperature plasma (LTP-Ti condition) demonstrated lower bacterial adhesion than the control (Ctrl-Ti) disks. ${ }^{*} p<0.05,{ }^{* *} p<0.01,{ }^{* * *} p<0.001$.

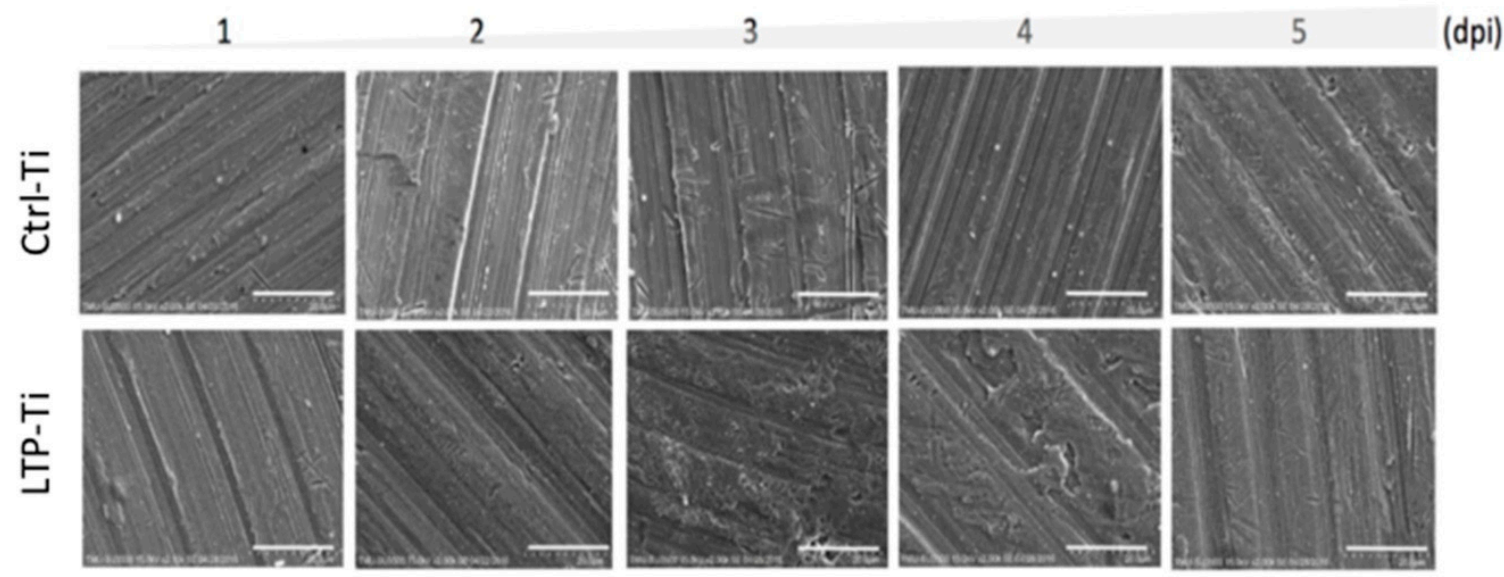

Figure 7. Effect of treatment on Porphyromonas gingivalis growth on the titanium disks. Disks treated with autoclaving only (Ctrl-Ti condition) and those treated with both autoclaving and low-temperature plasma (LTP; LTP-Ti condition) were exposed to P. gingivalis $\left(10^{6} \mathrm{CFU} / \mathrm{mL}\right)$ via incubation for up to $5 \mathrm{~d}$ after which they were harvested at the indicated time points. Representative scanning electron micrographs illustrate the bacterial growth. A relatively low number of bacterial colonies were observed on the LTP-Ti disks. Magnification: 2000x; scale bar: $20 \mu \mathrm{m}$.

Table 2. Growth of Porphyromonas gingivalis on the treated titanium disks.

\begin{tabular}{|c|c|c|c|c|c|}
\hline \multirow{2}{*}{ Treatment } & \multicolumn{5}{|c|}{ Culturing Days after $P$. gingivalis Cultured } \\
\hline & 1 & 2 & 3 & 4 & 5 \\
\hline Crtl-Ti & $63.10 \mathrm{cfu} / \mathrm{cm}^{2}$ & $1584.90 \mathrm{cfu} / \mathrm{cm}^{2}$ & $1,258,925.41 \mathrm{cfu} / \mathrm{cm}^{2}$ & $15,848,931.92 \mathrm{cfu} / \mathrm{cm}^{2}$ & $25,118,864.32 \mathrm{cfu} / \mathrm{cm}^{2}$ \\
\hline$p$-value & $* * * p<0.001$ & $* * * p<0.001$ & ${ }^{*} p<0.05$ & $* * *<<0.001$ & $* p<0.05$ \\
\hline
\end{tabular}

Unit: $\mathrm{cfu} / \mathrm{cm}^{2}$ 
Titanium disks treated with autoclaving only (Ctrl-Ti condition) and those treated with both autoclaving and low-temperature plasma (LTP-Ti condition) were exposed to $P$. gingivalis $\left(10^{6} \mathrm{CFU} / \mathrm{mL}\right)$ via incubation for up to $5 \mathrm{~d}$ and were harvested at the indicated time points. Data represent the quantified results from scanning electron micrographs. ${ }^{*} p<0.05,{ }^{* *} p<0.01{ }^{* * *} p<0.001$.

\section{Discussion}

LTP treatment has previously been identified as a method used in etching, sputtering, plasma ion implantation, and plasma polarization or as a spray on metal-based materials. The LTP treatment of Ti implant surfaces is shown to improve cell attachment via alteration of the surface roughness and wettability; both parameters were reduced after LTP treatment.

In a previous study, argon plasma was effective in removing impurities from commercially pure titanium surfaces [51]. The sputtering achieved with the argon LTP in this study helped inhibit the adhesion of $P$. gingivalis organisms that are obligate anaerobe bacteria associated with advanced periodontal disease, late colonizers on implant surfaces exposed to the oral environment, and associated with peri-implantitis [52]. LTP sputtering is a possible treatment to improve the surface topography and biofunctionality of the dental implants. Furthermore, LTP treatment in this study enhanced the spread of the osteoblast-like cells and their attachment to the titanium disks; simultaneously, it decreased P. gingivalis attachment and growth. These findings are consistent with those of Canullo et al. [42], who, after studying 720 disks with three different types of surfaces, concluded that LTP could be efficiently used to sterilize an implant surface contaminated with peri-implantitis. Annunziata et al. [41] assessed the effects of the argon plasma treatment on different titanium implant surfaces, previously exposed in vitro to bacterial contamination, and also concluded that LTP could be used efficiently to sterilize an implant surface contaminated with peri-implantitis. With regard to osteoblasts, Canullo et al. were only able to indicate a potential for osteoblast attachment and spreading due to LTP treatment; however, our study demonstrated that LTP treatment enhanced these actions. These results are consistent with previous findings suggesting the possibility of using LTP in the treatment of dental peri-implantitis and osseointegration. Although the bacterial adhesion of materials probably cannot be fully avoided after LTP treatment, it can be minimized and controlled via artificial means [53]. However, LTP treatment also decreased the Ti surface roughness; this is in accordance with previous findings with plasma sputtering, wherein the initial average roughness was $167 \mathrm{~nm}$ and the final average roughness was $92 \mathrm{~nm}$. These results can be related to the low current $(13.56 \mathrm{MHz})$ used in the LTP-Ti condition to treat the Ti disk surfaces [54].

In a recent study, Matos et al. created a 3-species biofilm composed of Streptococcus sanguinis, Actinomyces naeslundii, and Fusobacterium nucleatum onto commercially pure titanium surfaces coated with LTP [25]. They found that plasma treatments increased the wettability of commercially pure titanium surfaces. They also found that LTP treatment enhanced the surface free energy while maintaining the surface roughness properties of commercially pure titanium. The treated surface exhibited improved surface characteristics while keeping the bacterial proliferation under control. Matos et al. were able to conclude that the surface treatment of titanium implants with plasma technology is a viable, promising strategy for extending the longevity of dental implants. In this study, similar conclusions can be drawn even though LTP treatment was performed with sputtering on the Ti disk surfaces rather than a coating; both wettability and surfaces roughness decreased, and this facilitated the growth of the MG-63 cells but limited the colonization by P. gingivalis on the Ti disk surfaces. As some studies have indicated, rougher surface, wettability, and high surface energy increase bacterial colonization [55].

Results of the correlation analysis during initial P. gingivalis colonization confirmed that the attachment of the bacteria to the surface was positively mediated by its roughness; lower surface roughness led to less bacterial adhesion (data not shown). Thus, Ti implants with smoother surfaces after LTP at $85 \mathrm{~W}$ and $13.56 \mathrm{MHz}$ and with $100 \mathrm{mTorr}$ of argon gas at room temperature for $15 \mathrm{~min}$ treatment may reduce microbial adhesion during the initial infection phase, thereby decreasing 
inflammation and reducing the possibility of peri-implantitis. These findings reveal that LTP sputtering may be considered as a useful method for obtaining a smoother implant surface and can prevent $P$. gingivalis infections, without damaging the dental implant surface. Moreover, the posttreatment surface roughness decreased in the implant surfaces, suggesting that LTP sputtering could be used for peri-implantitis treatment for a longer duration and with better clinical results. However, LTP treatment did not stop the MG-63 cells from growing during the study period; this is because mechanical approaches, such as the ones used clinically to control and remove biofilm were not used in this study, and thus, the cells were allowed to grow on the disk surfaces.

\section{Conclusions}

Considering the limitations of the present study, it is appropriate to conclude that LTP sputtering is beneficial in the treatment of peri-implantitis, owing to the low levels of microbial adhesion, reduced incidence of inflammatory conditions, and the resultant reduction in the risk of developing peri-implantitis.

Author Contributions: Y.-H.P. and W.-J.C. conceived and designed the experiments; E.S., W.-L.Y., J.C.Y.L., P.-Y.T., and S.-J.L. performed the experiments; E.S., K.-C.Y., H.-M.H., and N.C.T. analyzed the data; W.L.Y., N.C.T., and W.-J.C. wrote the paper; and W.-J.C. founded this study.

Funding: This research received no external funding

Acknowledgments: The authors would like to thank Enago (www.enago.tw) for the English language review.

Conflicts of Interest: The authors declare that there is no conflict of interest regarding the publication of this paper.

\section{References}

1. Adell, R.; Lekholm, U.; Rockler, B.; Branemark, P.-I. A 15-year study of osseointegrated implants in the treatment of the edentulous jaw. Int. J. Oral Surg. 1981, 10, 387-416. [CrossRef]

2. Mengel, R.; Behle, M.; Flores-De-Jacoby, L. Osseointegrated Implants in Subjects Treated for Generalized Aggressive Periodontitis: 10-Year Results of a Prospective, Long-Term Cohort Study. J. Periodontol. 2007, 78, 2229-2237. [CrossRef] [PubMed]

3. Misch, C.E.; Perel, M.L.; Wang, H.L.; Sammartino, G.; Galindo-Moreno, P.; Trisi, P.; Steigmann, M.; Rebaudi, A.; Palti, A.; Pikos, M.A.; et al. Implant success, survival, and failure: The International Congress of Oral Implantologists (ICOI) Pisa Consensus Conference. Implant Dent. 2008, 17, 5-15. [CrossRef] [PubMed]

4. Kao, P.; Lee, N.; Sivathasan, D.; Zhu, J.; Polster, A.; Darby, I.; Cheung, M.C.; Kao, P.; Vong, C.W. Interest in dental implantology and preferences for implant therapy: A survey of Victorian dentists. Aust. Dent. J. 2016, 61, 455-463.

5. Branemark, P.-I.; Adell, R.; Albrektsson, T.; Lekholm, U.; Lundkvist, S.; Rockler, B. Osseointegrated titanium fixtures in the treatment of edentulousness. Biomaterials 1983, 4, 25-28. [CrossRef]

6. Scarano, A.; Piattelli, M.; Caputi, S.; Favero, G.A.; Piattelli, A. Bacterial Adhesion on Commercially Pure Titanium and Zirconium Oxide Disks: An in vivo human study. J. Periodontol. 2004, 75, 292-296. [CrossRef] [PubMed]

7. Berglundh, T.; Persson, L.; Klinge, B. A systematic review of the incidence of biological and technical complications in implant dentistry reported in prospective longitudinal studies of at least 5 years. J. Clin. Periodontol. 2002, 29, 197-212. [CrossRef] [PubMed]

8. Esposito, M.; Hirsch, J.M.; Lekholm, U.; Thomsen, P. Biological factors contributing to failures of osseointegrated oral implants. (I). Success criteria and epidemiology. Eur. J. Oral Sci. 1998, 106, 527-551. [CrossRef] [PubMed]

9. Sakka, S.; Baroudi, K.; Nassani, M.Z. Factors associated with early and late failure of dental implants. J. Investig. Clin. Dent. 2012, 3, 258-261. [CrossRef] [PubMed]

10. Leonhardt, A.; Renvert, S.; Dahlén, G. Microbial findings at failing implants. Clin. Oral Implant. Res. 1999, 10, 339-345. [CrossRef] 
11. Hultin, M.; Gustafsson, A.; Hallström, H.; Johansson, L.-A.; Ekfeldt, A.; Klinge, B. Microbiological findings and host response in patients with peri-implantitis. Clin. Oral Implant. Res. 2002, 13, 349-358. [CrossRef]

12. Mombelli, A. Microbiology and antimicrobial therapy of peri-implantitis. Periodontology 2000 2000, 28, 177-189. [CrossRef]

13. Tabanella, G.; Nowzari, H.; Slots, J. Clinical and Microbiological Determinants of Ailing Dental Implants. Clin. Implant. Dent. Relat. Res. 2009, 11, 24-36. [CrossRef] [PubMed]

14. Casado, P.L.; Otazu, I.B.; Balduino, A.; De Mello, W.; Barboza, E.P.; Duarte, M.E.L. Identification of Periodontal Pathogens in Healthy Periimplant Sites. Implant. Dent. 2011, 20, 226-235. [CrossRef] [PubMed]

15. Mombelli, A.; Lang, N.P. The diagnosis and treatment of peri-implantitis. Periodontology 2000 1998, $17,63-76$. [CrossRef] [PubMed]

16. Murray, C.M.; Knight, E.T.; Russell, A.A.; Tawse-Smith, A.; Leichter, J.W. Peri-implant disease: Current understanding and future direction. N. Z. Dent. J. 2013, 109, 55-62. [PubMed]

17. Kotsakis, G.A.; Konstantinidis, I.; Karoussis, I.K.; Ma, X.; Chu, H. Systematic Review and Meta-Analysis of the Effect of Various Laser Wavelengths in the Treatment of Peri-Implantitis. J. Periodontol. 2014, 85, 1203-1213. [CrossRef]

18. Wang, F.; Wu, Y.; Zou, D.; Wang, G.; Kaigler, D. Clinical outcomes of dental implant therapy in alveolar cleft patients: A systematic review. Int. J. Oral Maxillofac. Implant. 2014, 29, 1098-1105. [CrossRef]

19. Romanos, G.E.; Javed, F.; Delgado-Ruiz, R.A.; Calvo-Guirado, J.L. Peri-implant diseases: A review of treatment interventions. Dent. Clin. N. Am. 2015, 59, 157-178. [CrossRef]

20. Elemek, E.; Almas, K. Peri-implantitis: Etiology, diagnosis and treatment: An update. N. Y. State Dent. J. 2014, 80, 26-32.

21. Malek, R.; Fisher, J.G.; Caleca, A.; Stinson, M.; Van Oss, C.J.; Lee, J.Y.; Cho, M.I.; Genco, R.J.; Evans, R.T.; Dyer, D.W. Inactivation of the Porphyromonas gingivalis fimA gene blocks periodontal damage in gnotobiotic rats. J. Bacteriol. 1994, 176, 1052-1059. [CrossRef] [PubMed]

22. Kato, I.; Vasquez, A.A.; Moyerbrailean, G.; Land, S.; Sun, J.; Lin, H.-S.; Ram, J.L. Oral microbiome and history of smoking and colorectal cancer. J. Epidemiol. Res. 2016, 2, 92-101. [CrossRef] [PubMed]

23. Tribble, G.D.; Kerr, J.E.; Wang, B.-Y. Genetic diversity in the oral pathogen Porphyromonas gingivalis: Molecular mechanisms and biological consequences. Futur. Microbiol. 2013, 8, 607-620. [CrossRef] [PubMed]

24. Rodrigo, D.; Martin, C.; Sanz, M. Biological complications and peri-implant clinical and radiographic changes at immediately placed dental implants. A prospective 5-year cohort study. Clin. Oral Implant. Res. 2012, 23, 1224-1231. [CrossRef] [PubMed]

25. Lang, N.P.; Wilson, T.G.; Corbet, E.F. Biological complications with dental implants: Their prevention, diagnosis and treatment. Clin. Oral Implant. Res. 2000, 11, 146-155. [CrossRef]

26. Meschenmoser, A.; D’Hoedt, B.; Meyle, J.; Elßner, G.; Korn, D.; Hämmerle, H.; Schulte, W.; Meyle, J. Effects of Various Hygiene Procedures on the Surface Characteristics of Titanium Abutments. J. Periodontol. 1996, 67, 229-235. [CrossRef] [PubMed]

27. Placko, H.E.; Mishra, S.; Weimer, J.J.; Lucas, L.C. Surface characterization of titanium-based implant materials. Int. J. Oral Maxillofac. Implant. 2000, 15, 355-363.

28. Webb, K.; Caldwell, K.; Tresco, P.A. Fibronectin Immobilized by a Novel Surface Treatment Regulates Fibroblast Attachment and Spreading. Crit. Rev. Biomed. Eng. 2000, 28, 203-208. [CrossRef] [PubMed]

29. Wennerberg, A.; Albrektsson, T. Suggested guidelines for the topographic evaluation of implant surfaces. Int. J. Oral Maxillofac. Implant. 2000, 15, 331-344.

30. Mustafa, K.; Wroblewski, J.; Lopez, B.S.; Wennerberg, A.; Hultenby, K.; Arvidson, K. Determining optimal surface roughness of $\mathrm{TiO} 2$ blasted titanium implant material for attachment, proliferation and differentiation of cells derived from human mandibular alveolar bone. Clin. Oral Implant. Res. 2001, 12, 515-525. [CrossRef]

31. Kawashima, H.; Sato, S.; Kishida, M.; Yagi, H.; Matsumoto, K.; Ito, K. Treatment of Titanium Dental Implants with Three Piezoelectric Ultrasonic Scalers: An In Vivo Study. J. Periodontol. 2007, 78, 1689-1694. [CrossRef] [PubMed]

32. Chang, Y.-C.; Lee, W.-F.; Feng, S.-W.; Huang, H.-M.; Lin, C.-T.; Teng, N.-C.; Chang, W.J. In Vitro Analysis of Fibronectin-Modified Titanium Surfaces. PLoS ONE 2016, 11, e0146219. [CrossRef] [PubMed] 
33. Bürgers, R.; Hahnel, S.; Reichert, T.E.; Rosentritt, M.; Behr, M.; Gerlach, T.; Handel, G.; Gosau, M. Adhesion of Candida albicans to various dental implant surfaces and the influence of salivary pellicle proteins. Acta Biomater. 2010, 6, 2307-2313. [CrossRef] [PubMed]

34. Kim, J.H.; Lee, M.A.; Han, G.J.; Cho, B.H. Plasma in dentistry: A review of basic concepts and applications in dentistry. Acta Odontol. Scand. 2014, 72, 1-12. [CrossRef] [PubMed]

35. Hesby, R.M.; Haganman, C.R.; Stanford, C.M. Effects of radiofrequency glow discharge on impression material surface wettability. J. Prosthet. Dent. 1997, 77, 414-422. [CrossRef]

36. Özden, N.; Akaltan, F.; Suzer, S.; Akovali, G.; Akovalı, G. Time-related wettability characteristic of acrylic resin surfaces treated by glow discharge. J. Prosthet. Dent. 1999, 82, 680-684. [CrossRef]

37. Shibata, Y.; Hosaka, M.; Kawai, H.; Miyazaki, T. Glow discharge plasma treatment of titanium plates enhances adhesion of osteoblast-like cells to the plates through the integrin-mediated mechanism. Int. J. Oral Maxillofac. Implant. 2002, 17, 771-777.

38. Kawai, H.; Shibata, Y.; Miyazaki, T. Glow discharge plasma pretreatment enhances osteoclast differentiation and survival on titanium plates. Biomaterials 2004, 25, 1805-1811. [CrossRef]

39. Chang, Y.C.; Feng, S.W.; Huang, H.M.; Teng, N.C.; Lin, C.T.; Lin, H.K.; Wang, P.D.; Chang, W.J. Surface analysis of titanium biological modification with glow discharge. Clin. Implant Dent. Relat. Res. 2015, 17, 469-475. [CrossRef]

40. Chang, Y.C.; Ho, K.N.; Feng, S.W.; Huang, H.M.; Chang, C.H.; Lin, C.T.; Teng, N.C.; Pan, Y.H.; Chang, W.J. Fibronectin-Grafted Titanium Dental Implants: An In Vivo Study. BioMed Res. Int. 2016, 2016, 1-11.

41. Annunziata, M.; Canullo, L.; Donnarumma, G.; Caputo, P.; Nastri, L.; Guida, L. Bacterial inactivation/sterilization by argon plasma treatment on contaminated titanium implant surfaces: In vitro study. Medicina Oral Patología Oral y Cirugia Bucal 2016, 21, 118. [CrossRef] [PubMed]

42. Canullo, L.; Genova, T.; Wang, H.-L.; Carossa, S.; Mussano, F. Plasma of Argon Increases Cell Attachment and Bacterial Decontamination on Different Implant Surfaces. Int. J. Oral Maxillofac. Implant. 2017, 32, 1315-1323. [CrossRef] [PubMed]

43. Shon, W.J.; Chung, S.H.; Kim, H.K.; Han, G.J.; Cho, B.H.; Park, Y.S. Peri-implant bone formation of non-thermal atmospheric pressure plasma-treated zirconia implants with different surface roughness in rabbit tibiae. Clin. Oral Implant. Res. 2014, 25, 573-579. [CrossRef] [PubMed]

44. Coelho, P.G.; Giro, G.; Teixeira, H.S.; Marin, C.; Witek, L.; Thompson, V.P.; Tovar, N.; Silva, N.R.F.A. Argon-based atmospheric pressure plasma enhances early bone response to rough titanium surfaces. J. Biomed. Mater. Res. Part A 2012, 100, 1901-1906. [CrossRef] [PubMed]

45. Giro, G.; Tovar, N.; Witek, L.; Marin, C.; Silva, N.R.; Bonfante, E.A.; Coelho, P.G. Osseointegration assessment of chairside argon-based nonthermal plasma-treated Ca-P coated dental implants. J. Biomed. Mater. Res. Part A 2013, 101, 98-103. [CrossRef] [PubMed]

46. Ray, S.; Shard, A.G. Quantitative Analysis of Adsorbed Proteins by X-ray Photoelectron Spectroscopy. Anal. Chem. 2011, 83, 8659-8666. [CrossRef] [PubMed]

47. Salamanca, E.; Pan, Y.-H.; Tsai, A.I.; Lin, P.-Y.; Lin, C.-K.; Huang, H.-M.; Teng, N.-C.; Wang, P.D.; Chang, W.-J. Enhancement of Osteoblastic-Like Cell Activity by Glow Discharge Plasma Surface Modified Hydroxyapatite/ $\beta$-Tricalcium Phosphate Bone Substitute. Materials 2017, 10, 1347. [CrossRef]

48. Batsukh, N.; Feng, S.W.; Lee, W.F.; Leu, S.-J.; Tsai, P.-Y.; Ho, K.-N.; Lin, C.T.; Su, C.-H.; Chang, W.-J. Effects of Porphyromonas gingivalis on Titanium Surface by Different Clinical Treatment. J. Med. Biol. Eng. 2017, 37, 35-44. [CrossRef]

49. Erbektas, A.R.; Isgor, O.B.; Weiss, W.J. An accelerated testing protocol for assessing microbially induced concrete deterioration during the bacterial attachment phase. Cem. Concr. Compos. 2019, 104, 103339. [CrossRef]

50. Koch, A.L. Turbidity measurements of bacterial cultures in some available commercial instruments. Anal. Biochem. 1970, 38, 252-259. [CrossRef]

51. Aronsson, B.; Lausmaa, J.; Kasemo, B. Glow discharge plasma treatment for surface cleaning and modification of metallic biomaterials. J. Biomed. Mater. Res. 1997, 35, 49-73. [CrossRef]

52. Socransky, S.; Haffajee, A.; Cugini, M.; Smith, C.; Kent, R.L. Microbial complexes in subgingival plaque. J. Clin. Periodontol. 1998, 25, 134-144. [CrossRef] [PubMed]

53. Huang, H.-M.; Hsieh, S.-C.; Teng, N.-C.; Feng, S.-W.; Ou, K.-L.; Chang, W.-J. Biological surface modification of titanium surfaces using glow discharge plasma. Med. Biol. Eng. 2011, 49, 701-706. [CrossRef] [PubMed] 
54. Lin, C.-C.; Cheng, H.-C.; Huang, C.-F.; Lin, C.-T.; Lee, S.-Y.; Chen, C.-S.; Ou, K.-L. Enhancement of Biocompatibility on Bioactive Titanium Surface by Low-Temperature Plasma Treatment. Jpn. J. Appl. Phys. 2005, 44, 8590-8598. [CrossRef]

55. Matos, A.O.; Ricomini-Filho, A.P.; Beline, T.; Ogawa, E.S.; Oliveira, B.E.C.; De Almeida, A.B.; Junior, F.H.N.; Rangel, E.C.; Da Cruz, N.C.; Sukotjo, C.; et al. Three-species biofilm model onto plasma-treated titanium implant surface. Colloids Surf. B 2017, 152, 354-366. [CrossRef]

(c)

(C) 2019 by the authors. Licensee MDPI, Basel, Switzerland. This article is an open access article distributed under the terms and conditions of the Creative Commons Attribution (CC BY) license (http://creativecommons.org/licenses/by/4.0/). 